\title{
Selected-Control Hydrothermal Synthesis and Formation Mechanism of Monazite- and Zircon-type $\mathrm{LaVO}_{4}$ Nanocrystals
}

Weiliu Fan ${ }^{\dagger}$, Xinyu Song ${ }^{\ddagger}$, Yuxiang $\mathrm{Bu}^{\ddagger}$, Sixiu Sun ${ }^{\dagger \neq *}$, and Xian Zhao ${ }^{\dagger *}$,

State Key Laboratory of Crystal Materials, Shandong University,

Department of Chemistry, Shandong University, Jinan, 250100, People's Republic of China

\section{Supporting Information}
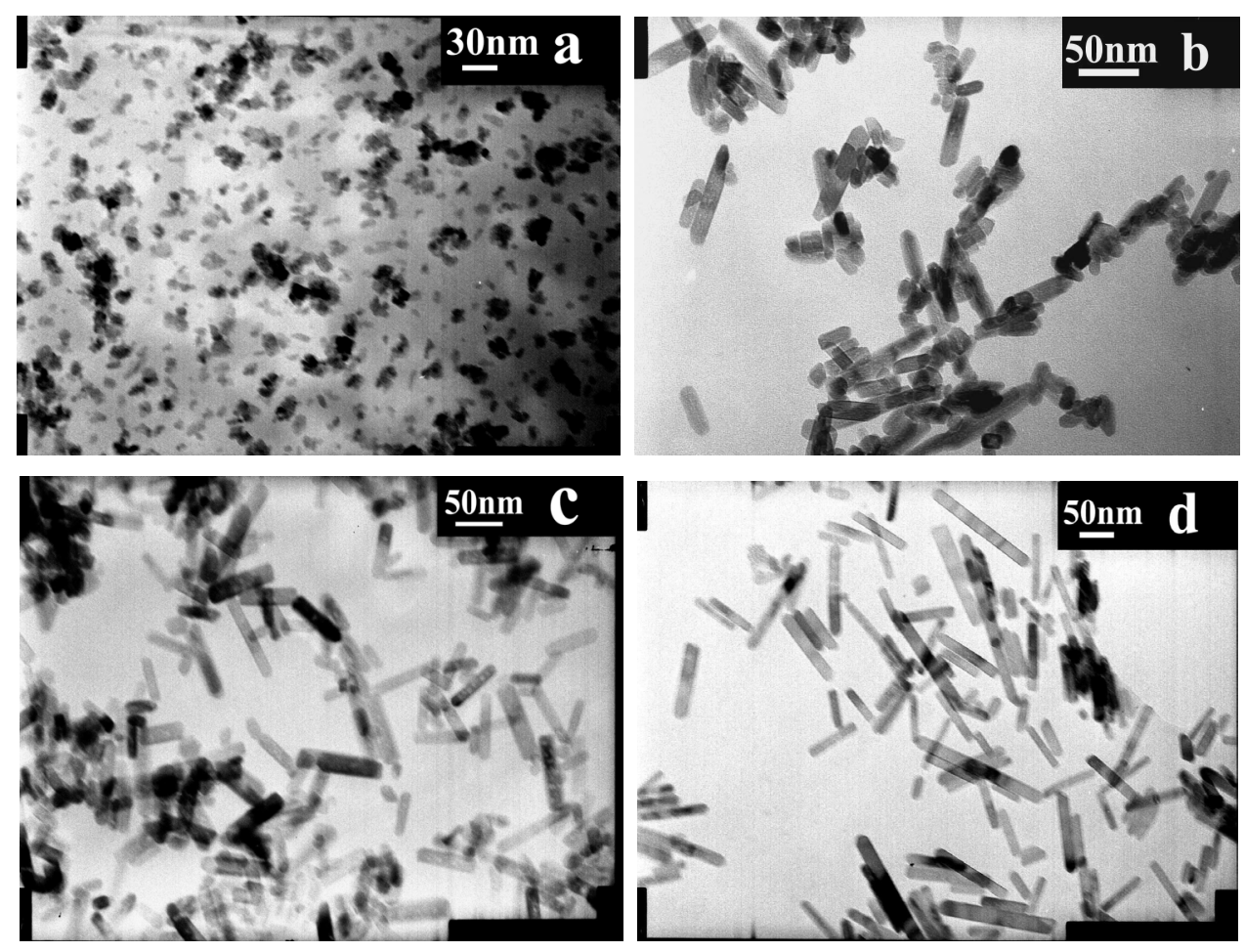

Figure S1. The corresponding TEM images of $\mathrm{LaVO}_{4}$ nanocrystals obtained under different hydrothermal temperature for $48 \mathrm{~h}$ at $\mathrm{pH}=4.5$ with $\mathrm{La}\left(\mathrm{NO}_{3}\right)_{3}$ as La source. (a) room temperature; (b) $100{ }^{\circ} \mathrm{C}$; (c) $120^{\circ} \mathrm{C}$; (d) $150{ }^{\circ} \mathrm{C}$.

* To whom all correspondences should be addressed. Tel: 86-531-88364879, Fax: 86-531-88564464, E-mail: fwl@sdu.edu.cn 

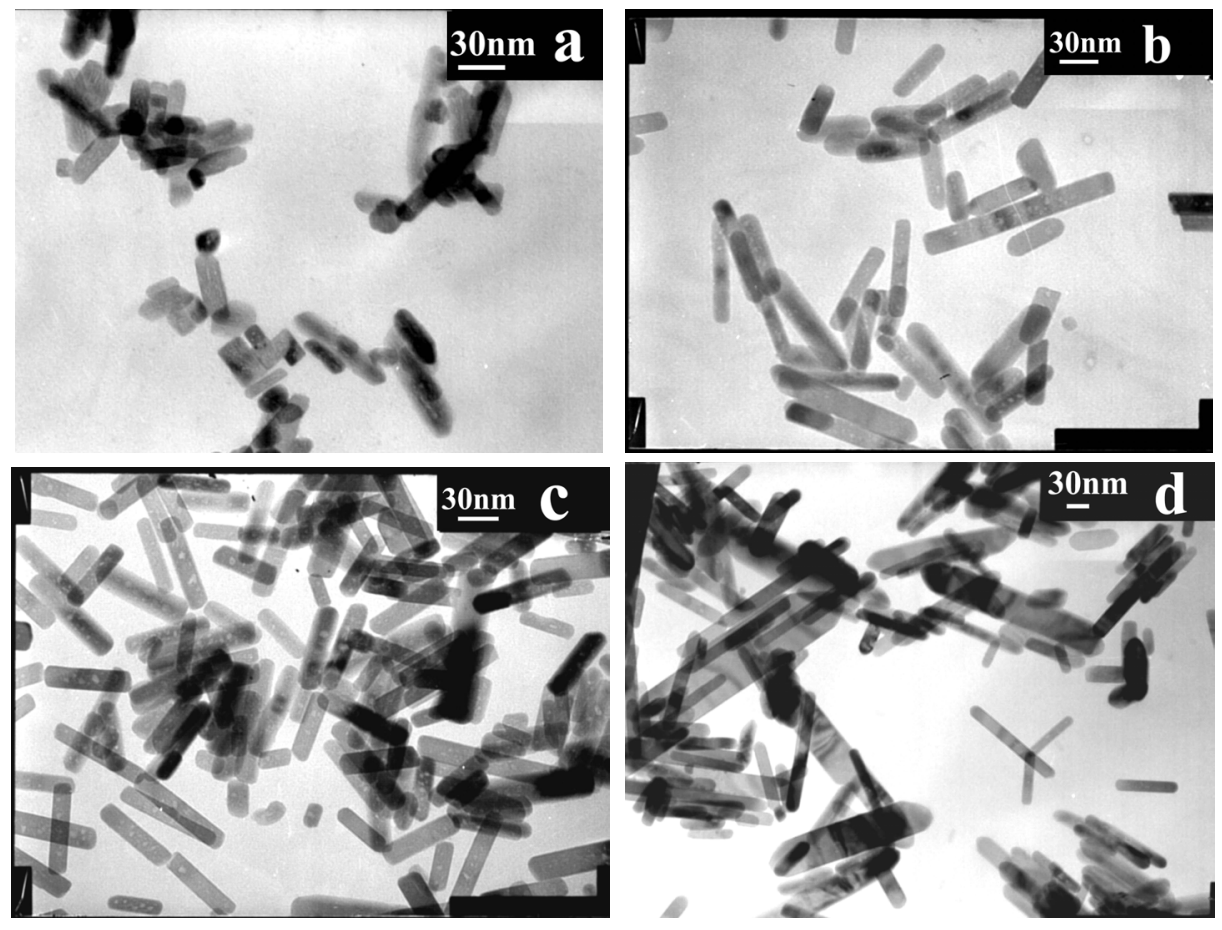

Figure S2. The corresponding TEM images of $\mathrm{LaVO}_{4}$ nanocrystals obtained under different hydrothermal time at $180{ }^{\circ} \mathrm{C}$ with $\mathrm{pH}=4.5$ and $\mathrm{La}\left(\mathrm{NO}_{3}\right)_{3}$ as La source. (a) $6 \mathrm{~h}$; (b) $12 \mathrm{~h}$; (c) $24 \mathrm{~h}$; (d) $60 \mathrm{~h}$. 